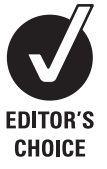

Department of Public Health,
Erasmus MC, University Medical Center Rotterdam, The

Netherlands; ${ }^{2}$ Netherlands Expert Center for Work-related Musculoskeletal Disorders, Erasmus MC, University Medical Center Rotterdam, The Netherlands; ${ }^{3}$ LOCOmotion, Bennekom, The Netherlands

${ }^{4}$ Expert Center Participation,

Work and Health, Rotterdam University of Applied Sciences, The Netherlands

Correspondence to:

A Burdorf, Erasmus MC

Department of Public Health

PO Box 2040

3000 CA Rotterdam

The Netherlands:

burdorf@erasmusmc.nl

Accepted 5 December 2008

Published Online First

18 February 2009

\title{
Determinants of implementation of primary preventive interventions on patient handling in healthcare: a systematic review
}

\author{
E Koppelaar, ${ }^{1,2}$ J J Knibbe, ${ }^{3}$ H S Miedema, ${ }^{2,4}$ A Burdorf ${ }^{1}$
}

\begin{abstract}
Objective: This systematic review aims (1) to identify barriers and facilitators during implementation of primary preventive interventions on patient handling in healthcare, and (2) to assess their influence on the effectiveness of these interventions.

Methods: PubMed and Web of Science were searched from January 1988 to July 2007. Study inclusion criteria included evaluation of a primary preventive intervention on patient handling, quantitative assessment of the effect of the intervention on physical load or musculoskeletal disorders or sick leave, and information on barriers or facilitators in the implementation of the intervention. 19 studies were included, comprising engineering $(n=10)$, personal $(n=6)$ and multiple interventions $(n=3)$. Barriers and facilitators were classified into individual and environmental categories of factors that hampered or enhanced the appropriate implementation of the intervention.
\end{abstract}

Results: 16 individual and 45 environmental barriers and facilitators were identified. The most important environmental categories were "convenience and easy accessibility" (56\%), "supportive management climate" (18\%) and "patient-related factors" (11\%). An important individual category was motivation (63\%). None of the studies quantified their impact on effectiveness nor on compliance and adherence to the intervention.

Conclusion: Various factors may influence the appropriate implementation of primary preventive interventions, but their impact on the effectiveness of the interventions was not evaluated. Since barriers in implementation are often acknowledged as the cause of the ineffectiveness of patient handling devices, there is a clear need to quantify the influence of these barriers on the effectiveness of primary preventive interventions in healthcare.

Among healthcare staff the prevalence of musculoskeletal disorders (MSDs) is higher than in most other occupations. ${ }^{1}$ Patient handling activities are a major cause of MSDs among nursing personnel. ${ }^{2}$ The high occurrence of MSDs has important consequences due to substantial health care utilisation, sickness absence and permanent disability. ${ }^{3} \mathrm{~A}$ wide range of primary preventive interventions have been developed in the past to reduce physical load related to patient handling and therefore decrease the occurrence of MSDs. Conflicting results have been found for engineering interventions such as lifting devices. ${ }^{45}$ There is strong evidence that personal interventions alone, such as training on preferred patient handling techniques, are not effective. ${ }^{67}$ Either these techniques did not reduce the risk of back injury or the training did not lead to adequate change in lifting and handling techniques.' Administrative interventions, targeting work practices and policies, are often an integral part of a more comprehensive intervention. There is moderate evidence for the effectiveness of multidimensional interventions, which are being applied more often recently. ${ }^{4}{ }^{6}$ Nelson and Baptiste described several barriers in the implementation of patient handling devices, such as patient aversion, difficulty in use, time constraints, and insufficient numbers of available lifting devices. ${ }^{5}$ Dawson et al reported poor compliance as a possible cause of the ineffectiveness of the implementation of a personal intervention in home care. ${ }^{4}$ The actual influence of such barriers on the effectiveness of interventions is, however, seldom taken into account.

The results of interventions will depend not only on the effectiveness of the intervention itself but also on appropriate implementation in the actual work situation. ${ }^{8}$ Grol and Grimshaw have emphasised the importance of the different steps which need to be taken in the implementation stage of an intervention. ${ }^{9}$ An important procedure in the implementation process is the identification of obstacles to change work practices, which may arise at the level of the individual as well as in the wider environment. ${ }^{9}$ Individual factors refer to variables within the person, such as motivation, attitude and a person's belief in his or her ability to use the intervention. ${ }^{10}$ Environmental factors refer to the social and physical context in which a person needs to function. ${ }^{11-13}$ Although several barriers to effective implementation of patient handling devices have been identified in intervention studies, there is little insight into their impact on the effectiveness of these interventions. ${ }^{8} 1415$

Therefore, the aims of this systematic review are (1) to identify barriers and facilitators during the implementation of primary preventive interventions aimed at patient handling in healthcare, and (2) to assess the influence of these barriers and facilitators on the effectiveness of these interventions.

\section{METHODS}

\section{Identification and selection of articles}

PubMed and Web of Science were searched from January 1988 to July 2007 to identify relevant articles. The following keywords were used in the search strategy: (1) patient handling or patient transfer AND intervention or prevent* or ergo*; and (2) physical load or physical exposure or 


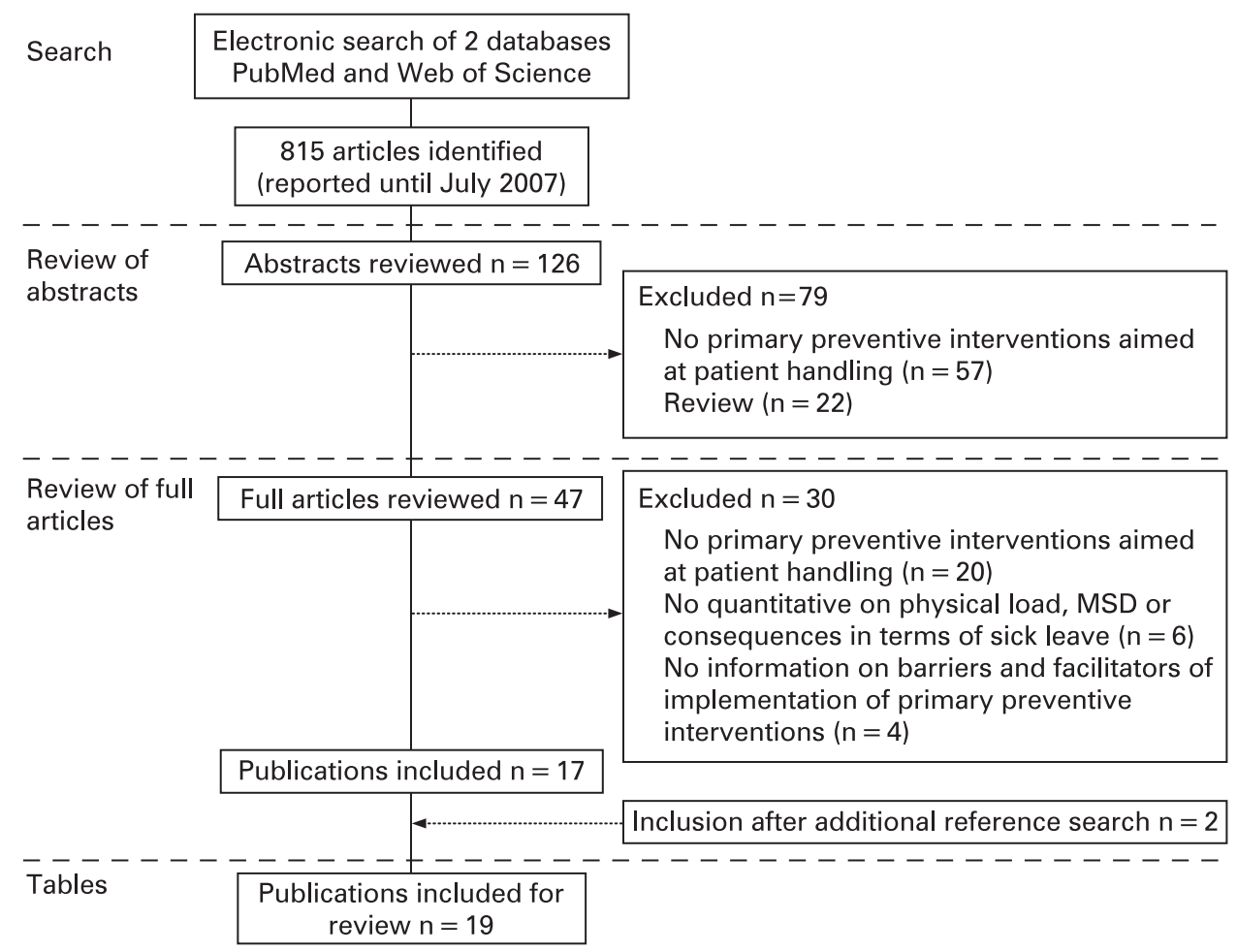

Figure 1 Overview of the literature search and review strategy.

mechanical exposure or musculoskeletal disorder or musculoskeletal injury.

An article was included if the following inclusion criteria were met: (1) it was a study on a primary preventive intervention aimed at preventing or reducing physical load related to patient handling, as characterised by a reduction in awkward postures, strenuous movements and forceful exertions; (2) it provided quantitative information on one of the following outcome measures: physical load, musculoskeletal disorders or musculoskeletal sick leave (lost working time); (3) it provided information on barriers or facilitators in the implementation of a primary preventive intervention; and (4) it was written in English.

The selection of articles was conducted in two steps. First, all abstracts or titles found by the electronic searches were checked by two authors (EK and $A B$ ). Second, after obtaining copies of eligible articles, two authors (EK and JJK) independently assessed the articles for inclusion criteria. Disagreements were solved by consensus and, if necessary, by third party (AB) adjudication. The electronic search identified 126 abstracts of potential interest and the articles of 47 of these were considered for full review. Seventy nine abstracts were not eligible for further scrutiny, primarily because they failed to meet the first inclusion criterion (fig 1).

After full review, 17 of the 47 potentially relevant articles were included. The main reasons for excluding 30 articles were: no primary preventive interventions aimed at patient handling $(n=20)$; no quantitative information on physical load, MSD or their consequences in terms of sick leave (lost working time) $(n=6)$; and no information on barriers and facilitators in the implementation of primary preventive interventions $(n=4)$. Some articles were excluded for several reasons.

The search was extended by screening the reference lists of the 17 articles included and this resulted in two further articles being selected. Thus, 19 articles in total were included in this systematic review.

\section{Data extraction}

Two authors (EK and JJK) performed the data extraction independently of each other according to a standardised format. Information was collected on study population, study design, study duration, outcome measures, type of primary preventive intervention, barriers and facilitators of the implementation of the intervention, and their effects with regard to the outcome measures. The studies included were categorised into four types of intervention ${ }^{15}$ :

1. Engineering intervention (intervention targeting the physical work environment)

2. Personal intervention (intervention addressing personal behaviour through education and training)

3. Administrative intervention (intervention focusing primarily on organisational strategies targeting work practices and policies)

4. Multiple interventions (a combination of two or more of the above interventions).

\section{Barriers and facilitators}

Barriers were defined as factors that hampered the implementation of primary preventive interventions. Facilitators were defined as factors that enhanced the implementation of primary preventive interventions.

Two intertwined approaches were used to identify individual and environmental barriers and facilitators (table 1). The approach of Rothschild ${ }^{16}$ is oriented towards individual factors, whereas the approach of Shain and $\mathrm{Kramer}^{17}$ primarily focuses on the environmental context (table 1). Rothschild has defined three categories: motivation, ability and opportunity. ${ }^{16}$ Motivation is the willingness of individuals to undertake the 
necessary actions to commit to the intervention. Ability refers to the capability of individuals to do something that requires specific skills, knowledge, experience and attitude. Opportunity relates to the environment in which the intervention is implemented and was further specified by the approach of Shain and Kramer. Shain and Kramer have distinguished the categories social support, management support, supportive management climate, convenience and easy accessibility, interactivity, wide appeal, employee participation and self-efficacy. ${ }^{17}$ Employee participation and self-efficacy belong to the individual factors category and were also included in the categories of Rothschild. Social support embraces the supportiveness of family, friends, co-workers and others for the intervention. Convenience of use and easy accessibility relates to the availability of resources such as enough time to transfer patients, sufficient lifting devices, and trained staff. Management support includes the commitment of employers to the intervention. Supportive management climate refers to a work situation where the intervention is being promoted rather than hindered. Wide appeal is the attractiveness of the intervention to a broad variety of workers. Interactivity covers the reinforcement of an intervention by other work practices. In healthcare, the patient is an additional important environmental factor, encompassing the physical and cognitive capabilities of the patients, as well as the attitudes of the patients towards the intervention. ${ }^{12}$ Within each category multiple factors can be reported as barriers or facilitators.

\section{Data analysis}

The barriers and facilitators were classified as individual or environmental factors. When possible, the qualitative and quantitative effect of the barrier or facilitator on the effectiveness of the intervention was established.

\section{RESULTS}

Table 1 describes the 45 environmental $(B=27, F=18)$ and 16 individual $(B=9, F=7)$ barriers $(B)$ and facilitators $(F)$ reported in 19 studies. The most important environmental categories were "convenience and easy accessibility" (56\%), "supportive management climate" (18\%) and "patient-related factors" (11\%). The individual category "motivation" was mentioned most often (10 times in eight studies).

The selected studies are presented in tables $2-4$ according to type of intervention. Ten studies were classified as engineering interventions, ${ }^{12}{ }^{13}{ }^{18-25}$ six as personal interventions, ${ }^{11}{ }^{26-30}$ and three as multiple interventions. ${ }^{31-33}$ Nine of the 19 studies described both individual and environmental barriers and facilitators. ${ }^{11-13} 182526283033$ Eight studies described only environmental barriers and facilitators ${ }^{19-22} 24293132$ and two studies ${ }^{23} 27$ described only individual barriers and facilitators. Overall, $42 \%$ of the studies $(n=8)$ described one or two barriers or facilitators, $42 \%$ of the studies $(n=8)$ three to five barriers or facilitators, and $16 \%$ of the studies $(n=3)$ more than five barriers or facilitators.

\section{Engineering interventions}

Table 2 describes 10 interventions introducing lifting equipment: three studies showed a significant reduction in the occurrence of MSDs, five studies reported positive but not statistically significant effects on MSDs, one study was inconclusive, and one study had contradictory results. In total, 31 barriers and facilitators were reported, of which 74\% (23 of 31) were classified as environmental factors. Overall, $52 \%$ (16 of 31) of these environmental barriers and facilitators could be placed in the category "convenience and easy accessibility", such as time to transfer patient with lifting device $(n=5)$, time required to implement intervention $(n=2)$ and availability of the lifting devices $(n=2)$. Other environmental factors were "patient" ( $\mathrm{n}=4)$ and "supportive management climate" $(\mathrm{n}=2)$. The individual category "motivation" was described in three studies and "ability" in five studies.

\section{Personal interventions}

Table 3 presents six interventions on training and education on patient handling techniques, use of engineering devices, and identification of workplace design problems. Five of the six studies showed no effect on the occurrence of MSDs. Two studies described training in the use of available transfer devices at the worksite, one of which showed a reduction in the occurrence of MSDs. In spite of the fact that transfer devices were available in the hospitals, the studies were categorised as personal intervention because evaluation of the intervention was specifically aimed at the training programme.

In total, 20 barriers and facilitators were described, of which $65 \%$ (13 of 20) were classified as environmental factors, most notably the category "convenience and easy accessibility" $(n=4)$. In addition, $86 \%$ (6 of 7 ) of the individual barriers and facilitators were categorised into "motivation", often referring

Table 1 Classification and summary of barriers and facilitators in the implementation of primary preventive interventions aimed at patient handling in health care

\begin{tabular}{|c|c|c|c|c|}
\hline $\begin{array}{l}\text { Type of barrier and } \\
\text { facilitator and source }\end{array}$ & Category & $\begin{array}{l}\text { No } \\
\text { of studies }\end{array}$ & $\begin{array}{l}\text { No of } \\
\text { barriers (B) }\end{array}$ & $\begin{array}{l}\text { No of } \\
\text { facilitators } \\
\text { (F) }\end{array}$ \\
\hline \multirow[t]{2}{*}{$\begin{array}{l}\text { 1. Individual (Rothschild } \\
\text { et al 1999) }\end{array}$} & $\begin{array}{l}\text { A. Motivation: willingness of individuals to undertake the necessary actions to commit to the } \\
\text { intervention }\end{array}$ & 8 & 6 & 4 \\
\hline & $\begin{array}{l}\text { B. Ability: capability of individuals to do something that requires specific skills, knowledge, } \\
\text { experience and attitude }\end{array}$ & 6 & 3 & 3 \\
\hline \multirow[t]{6}{*}{$\begin{array}{l}\text { 2. Environment (Shain } \\
\text { and Kramer 2004) }\end{array}$} & $\begin{array}{l}\text { A. Social support: supportiveness of family, friends, co-workers and others towards the } \\
\text { intervention }\end{array}$ & 3 & 1 & 2 \\
\hline & $\begin{array}{l}\text { B. Convenience and easy accessibility: availability of resources such as enough time to transfer } \\
\text { patients, enough lifting devices, trained staff, etc }\end{array}$ & 14 & 18 & 7 \\
\hline & C. Management support: commitment of employers to the intervention & 1 & - & 2 \\
\hline & $\begin{array}{l}\text { D. Supportive management climate: organisation of work in ways that promote rather than hinder } \\
\text { the intervention }\end{array}$ & 5 & 4 & 4 \\
\hline & E. Wide appeal: attractiveness of the intervention to a wide variety of workers & 1 & 1 & - \\
\hline & F. Interactivity: reinforcement of the intervention by other work practices & 1 & - & 1 \\
\hline Evanoff et al, $2003^{12}$ & G. Patient-related factors & 4 & 3 & 2 \\
\hline
\end{tabular}


Table 2 Studies with barriers and facilitators in the implementation of engineering interventions aimed at patient handling in health care

\begin{tabular}{|c|c|c|c|c|}
\hline Study & $\begin{array}{l}\text { Design } \\
\text { (duration) }\end{array}$ & $\begin{array}{l}\text { Population } \\
\text { (setting) }\end{array}$ & Intervention & Outcomes \\
\hline $\begin{array}{l}\text { Chhokar et al } \\
(2005)^{19}\end{array}$ & $\begin{array}{l}\text { OBS } \\
\text { (3 years) }\end{array}$ & $\begin{array}{l}\text { All staff who } \\
\text { handle patients } \\
\text { (nursing home) }\end{array}$ & $\begin{array}{l}65 \text { ceiling lifts and } \\
\text { education on use }\end{array}$ & $\begin{array}{l}\text { Significant reduction in } \\
\text { MSI claims, claims } \\
\text { costs and days lost }\end{array}$ \\
\hline $\begin{array}{l}\text { Engst et al } \\
(2005)^{20}\end{array}$ & CT (1 year) & $\begin{array}{l}34 \text { care staff INT, } \\
16 \text { care staff CON } \\
\text { (hospital) }\end{array}$ & $\begin{array}{l}\text { (1) Ceiling lifts and } \\
\text { training session to } \\
\text { introduce lifts; (2) no } \\
\text { intervention }\end{array}$ & $\begin{array}{l}\text { Decreased total claim } \\
\text { costs, but increased } \\
\text { claim costs associated } \\
\text { with repositioning } \\
\text { patients }\end{array}$ \\
\hline $\begin{array}{l}\text { Evanoff et al } \\
(2003)^{12}\end{array}$ & $\begin{array}{l}\text { OBS } \\
(2-3 \\
\text { years })\end{array}$ & $\begin{array}{l}36 \text { nursing units } \\
\text { (hospital and } \\
\text { nursing home) }\end{array}$ & $\begin{array}{l}25 \text { full-body and } 22 \\
\text { stand-up lifts and } \\
\text { instructional course on lift } \\
\text { operation }\end{array}$ & $\begin{array}{l}\text { Significant decrease in } \\
\text { MSI, lost workday } \\
\text { injuries and total lost } \\
\text { days due to injury }\end{array}$ \\
\hline
\end{tabular}

Type of barrier (B) or facilitator (F)

Time required to fully implement intervention (B-2B)

Time required to alter work culture (B-2B)

Ceiling lifts require more time than manually repositioning residents (B-2B)

Think they do not need lifting devices (B-1A)

Lack of knowledge (B-1B)

Too time consuming (B-2B)

Devices misplaced or not enough available (B-2B)

Patients in isolation/connected to too many lines (B-2B)

Aides or patient care technicians use lifting devices (F-2B)

Policy of mandatory lift usage (F-2D)

Patients do not like lifting devices/feels unstable (B-2G)

Established care activities and patient characteristics (F-2G)

Significant decrease in Lower employee-to-ergonomic device ratio (F-2B)

Financial support and ergonomic consultation for installing ergonomic devices

Hoist, walking belt, shower chairs and training in use of devices

$\begin{array}{lll}\text { Garg and Owen } & \text { OBS } & \text { 57 nursing } \\ (1992)^{22} & \begin{array}{l}\text { assistants in 2 } \\ \text { months) }\end{array} & \begin{array}{l}\text { units (nursing } \\ \text { home) }\end{array}\end{array}$

$\begin{array}{lll}\text { Li et al } & \text { OBS } & \begin{array}{l}138 \text { nurses in } 3 \\ \text { (2004) }\end{array} \\ \text { (7 months) } & \begin{array}{l}\text { nursing units } \\ \text { (hospital) }\end{array}\end{array}$

Miller et al CT (1 year) $(2006)^{23}$

$\begin{array}{ll}\text { Owen et al } & \text { CT } \\ (2002)^{24} & (5 \text { years })\end{array}$

Ronald et al OBS $(2002)^{13} \quad$ (5 years)

34 RNs and 95 aides (hospital)

45 nurses INT and 29 nurses CON (nursing home)

37 nurses INT and 20 nurses CON (hospital)

$\begin{array}{ll}\text { Yassi et al } & \text { RCT } \\ (2001)^{25} & (1 \text { year })\end{array}$

1 portable full-body sling lift, 2 stand-up sling lifts and a single hands-on training session on lift usage

(1) Portable ceiling lifts and training with regard to the ceiling lift; (2) no intervention

(1) 5 assistive devices and training in use;

(2) traditionally scheduled in-service training

62 ceiling lifts and training in use
103 nurses INT,

116 nurses INT and 127 nurses CON (hospital)
Number of injuries and lost-day injuries decreased

Decreased MSI claims and claim costs

Decreased number of back injuries, lost work and restricted days

No significant reduction in total MSI. Significant decline in MSI due to lifting and transferring

(1) Training in back care, patient assessment, and handling techniques using manual equipment;

(2) training in back care, patient assessment, and handling techniques using mechanical and other assistive equipment;

(3) no intervention
Number of injuries did not change significantly
Adequate staffing (F-2B)

Saves time to perform transfer with 1 nursing assistant ( $\mathrm{F}-2 \mathrm{~B})$

Reduction in number of patient transfers compensated for longer transfer times associated with devices (F-2B)

Lack of perceived need (B-1A)

Inexperience in lift use (B1B)

Lack of time (B-2B)

Lack of manoeuvring space (B-2B)

Staff turnover (B-2B)

Ceiling lifts preferred method for lifting and transferring (F-1B)

Patient more comfortable and secure when assistive devices used (F-2G)

Preference by staff for mechanical options (F-1B) Ceiling lifts not used for repositioning due to problems with slings (B-2B)

Incompatibility with pre-existing structures of older building $(\mathrm{B}-2 \mathrm{~B})$

Increased perception of safety among staff (F-1A)

More comfortable performing patient-handling tasks (F-1B)

Increasing demand by staff for mechanical equipment $(\mathrm{F}-2 \mathrm{~A})$

Other workplace dynamics than patient population (B-2D)

Changing patient population (B-2G)

\footnotetext{
CON, control group; CT, controlled trial; INT, intervention group; MSD, musculoskeletal disorders; MSI, musculoskeletal injuries; OBS observational study; RCT, randomised controlled trial. Type of barrier: B-2B represents a barrier (B), within environment (2), category B (convenience and easy accessibility).
}

to attitudes towards intervention $(n=2)$ and working techniques seen as good methods $(n=2)$. All other individual and environmental categories were mentioned at least once as a barrier or facilitator, except for patient-related factors.

\section{Multiple interventions}

Table 4 describes three multidimensional interventions which resulted in a significant reduction in MSDs. All three interventions involved lifting devices and peer leader roles or committees as part of the multidimensional intervention. In total, 10 barriers and facilitators were described, of which $90 \%$ (nine of 10) were classified as environmental factors. Overall, $65 \%$ (five of nine) of the environmental barriers and facilitators were in the category "convenience and easy accessibility", such as high staff turnover rates and initial investment not easily allocated. Other environmental categories were "supportive management climate" ( $\mathrm{n}=3$ ) and "patient" $(\mathrm{n}=1)$. The individual category "motivation" was described in one study where patient handling equipment was well accepted by staff. 
Table 3 Studies with barriers and facilitators in the implementation of personal interventions aimed at patient handling in health care

\begin{tabular}{|c|c|c|c|c|c|}
\hline Study & $\begin{array}{l}\text { Design } \\
\text { (duration) }\end{array}$ & $\begin{array}{l}\text { Population } \\
\text { (setting) }\end{array}$ & Intervention & Outcomes & Type of barrier $(B)$ or facilitator $(F)$ \\
\hline $\begin{array}{l}\text { Best } \\
(1997)^{11}\end{array}$ & $\begin{array}{l}\text { RCT } \\
\text { (1 year) }\end{array}$ & $\begin{array}{l}18 \text { staff INT and } \\
37 \text { staff CON } \\
\text { (nursing home) }\end{array}$ & $\begin{array}{l}\text { (1) } 32 \mathrm{~h} \text { training in techniques to } \\
\text { decrease lifting using semi-squat } \\
\text { posture and weight transfer } \\
\text { techniques such as bracing, } \\
\text { pivoting, lunging and } \\
\text { counterbalancing the load; }(2,3) \text { in- } \\
\text { house orientation training }\end{array}$ & $\begin{array}{l}\text { No significant } \\
\text { difference in back pain } \\
\text { after } 12 \text { months }\end{array}$ & $\begin{array}{l}\text { Influenced attitude of staff through delay in } \\
\text { opening nursing homes (B-1B) } \\
\text { Nurses wanting to transfer the patient "the old } \\
\text { way" (B-2A) } \\
\text { Variety of skill and knowledge levels due to staff } \\
\text { turnover (B-2B) }\end{array}$ \\
\hline
\end{tabular}

$\begin{array}{lll}\text { Feldstein et al } & \text { CT } & 50 \text { subjects INT } \\ (1993)^{26} & \text { (1 month) } & \text { and 25 subjects } \\ & & \text { CON (hospital) }\end{array}$

$\begin{array}{ll}\text { Johnsson } & \text { OBS } \\ \text { et al }(2002)^{27} & (6 \text { months })\end{array}$

51 nursing assistants (hospital and primary care)

$\begin{array}{lll}\text { Lagerstrom } & \text { OBS } & \begin{array}{l}348 \\ \text { et al }(1998)^{28}\end{array} \\ & \text { (3 years) } & \begin{array}{l}\text { participants } \\ \text { (hospital) }\end{array}\end{array}$

Pretest 164 nurses, posttest 59 trained nurses and 45 controls (hospital)

$\begin{array}{lll}\begin{array}{l}\text { Peterson et al } \\ (2004)^{30}\end{array} & \text { CT } & 2 \text { units INT and } \\ & \text { (1 month) } & \begin{array}{l}1 \text { unit CON } \\ \text { (nursing home) }\end{array}\end{array}$

(1) $2 \mathrm{~h}$ teaching session in correct body mechanics, patient transfer reinforcement of proper use of equipment, and problem identification regarding practical time on units over 2 weeks; (2) no intervention Training in patient handling methods and moving skills, physical and psychosocial risk factors, balance between patient's need for rehabilitation and use of lifting aids and workplace design, and awareness of body Education and training program in patient transfer technique and how and when to use lifting devices, physical fitness exercise and stress management techniques, one-on-one assistance, environmental hazards, and $8 \mathrm{~h}$ of movements; 2 learning models
No significant change in back pain and back fatigue.

No significant reduction in musculoskeletal symptoms
No decease in musculoskeletal problems
Nurses put patients first (B-1A)

Nurses concerned over loss of continuity of care to patients during program participation (B-1A) Low moral after nursing strike ending shortly before study began (B-1A)

Items taught on the course go against the work culture of the nurses $(\mathrm{B}-2 \mathrm{E})$

Patient handling methods seen as good $(\mathrm{F}-1 \mathrm{~A})$

Working technique was appreciated by nurses (F-1A)

Need for common work technique emphasised by different actors, such as the occupational health care department, the labour unions and nursing personnel $(\mathrm{F}-2 \mathrm{~A})$

All nursing personnel educated and trained at the same time (F-2B)

Management's detailed knowledge of personnel working conditions and needs (F-2C)

Need for common work technique according to management (F-2C)

Management applied for money to carry out the program (F-2D)

Hospital already well-equipped with transfer devices (F-2D)

Permanent component of competence training for nursing staff by continuous follow-up $(\mathrm{F}-2 \mathrm{~F})$
(1) Back injury training program in back injury risk factors, risky activities, control strategies including engineering controls, administrative controls, use of proper body mechanics when handling patients; (2) staff not attending to training

Training in correct ergonomic work practices, administrative strategies, and use of engineering controls: (1) only NAs trained, reinforced by RA; (2) all nurses trained, training reinforced by daily supervision from the registered nurses and licensed practical nurses; (3) no training
Reduction in number of reported lost-time back injuries from 7 in the first three quarters of 1996 to 1 in the fourth quarter of 1996

No significant difference in pain/ discomfort survey

CON, control group; CT, controlled trial; INT, intervention group; NA, nursing assistant; OBS, observational study; RA, research assistant; RCT, randomised controlled trial. Type of barrier: B-1B represents a barrier (B), within individual (1), category B (ability).

\section{Influence of barriers and facilitators on effectiveness}

None of the studies presented a quantitative evaluation of the influence of the barriers and facilitators during implementation on the effectiveness of the interventions. One study included the assessment of barriers for usage of lifting devices in the study design by interviewing nurses during the intervention period. ${ }^{12}$ The influence of these barriers on the effectiveness of the intervention was, however, not evaluated. In five studies barriers and facilitators were assigned retrospectively by the researcher as possible factors having influenced the effectiveness of the intervention. 121319213133

\section{DISCUSSION}

This review showed that various individual and environmental factors were of importance when implementing primary preventive interventions in the actual work situation. A key issue in the implementation of primary preventive interventions appeared to be the environmental category "convenience and easy accessibility", for example, time required to transfer patients, staff situation, and availability of lifting devices. Barriers and facilitators in the studies were identified retrospectively and their importance was described in qualitative terms. None of the studies carried out a quantitative evaluation 
Table 4 Studies with barriers and facilitators in the implementation of multiple interventions aimed at patient handling in health care

\begin{tabular}{|c|c|c|c|c|c|}
\hline Study & $\begin{array}{l}\text { Design } \\
\text { (duration) }\end{array}$ & $\begin{array}{l}\text { Population } \\
\text { (setting) }\end{array}$ & Intervention & Outcomes & Type of barrier $(B)$ or facilitator $(F)$ \\
\hline $\begin{array}{l}\text { Charney et al } \\
(2006)^{31}\end{array}$ & $\begin{array}{l}\text { OBS } \\
(1-4 \\
\text { years, } \\
\text { average } 2 \\
\text { years) }\end{array}$ & $\begin{array}{l}31 \text { hospitals } \\
\text { (hospital) }\end{array}$ & $\begin{array}{l}\text { Zero-lift program: (1) replace } \\
\text { manual lifting with mechanical } \\
\text { lifting; (2) written policy and } \\
\text { procedures supporting } \\
\text { mechanisation of lifting; } \\
\text { (3) training; (4) zero-lift committee; } \\
\text { and (5) patient screening procedure } \\
\text { to determine ambulatory level of } \\
\text { new patients }\end{array}$ & $\begin{array}{l}\text { Significant reduction } \\
\text { in time-lost injuries } \\
\text { and frequency of } \\
\text { injuries }\end{array}$ & $\begin{array}{l}\text { Initial investment not easily allocated in some } \\
\text { hospitals (B-2B) } \\
\text { Initiated with less equipment and later } \\
\text { augmented when funds were available (B-2B } \\
\text { High staff turnover rates (B-2B) } \\
\text { Mandatory use of equipment (F-2D) } \\
\text { No standardised assessment of patient } \\
\text { ambulatory status (B-2D) } \\
\text { Each hospital put their individual stamp on the } \\
\text { zero-lift model (B-2D) }\end{array}$ \\
\hline $\begin{array}{l}\text { Knibbe and Friele } \\
(1999)^{32}\end{array}$ & CT (1 year) & $\begin{array}{l}139 \text { subjects } \\
\text { INT and } 239 \\
\text { subjects CON } \\
\text { (home care) }\end{array}$ & $\begin{array}{l}\text { (1) Patient hoists (40); (2) training; } \\
\text { (3) introduction of } 12 \text { specially } \\
\text { trained lifting coordinators; (4) no } \\
\text { intervention }\end{array}$ & $\begin{array}{l}\text { Significant reduction } \\
\text { in back pain } \\
\text { prevalence and in total } \\
\text { number of transfers }\end{array}$ & $\begin{array}{l}\text { Relatives able to care for patients with use of } \\
\text { hoist without presence of nurse (F-2B) }\end{array}$ \\
\hline $\begin{array}{l}\text { Nelson et al } \\
(2006)^{33}\end{array}$ & $\begin{array}{l}\text { OBS } \\
\text { (9 months) }\end{array}$ & $\begin{array}{l}23 \text { high risk } \\
\text { units in } 7 \\
\text { facilities (home } \\
\text { care and } \\
\text { hospital) }\end{array}$ & $\begin{array}{l}6 \text { program elements: (1) ergonomic } \\
\text { assessment protocol; (2) patient } \\
\text { handling assessment criteria and } \\
\text { decision algorithms; (3) peer leader } \\
\text { role, "back injury resource nurses"; } \\
\text { (4) state-of-the-art equipment; } \\
\text { (5) after action reviews; and (6) no } \\
\text { lift policy }\end{array}$ & $\begin{array}{l}\text { Significant reduction } \\
\text { in injury rates and } \\
\text { modified duty days }\end{array}$ & $\begin{array}{l}\text { Patient handling equipment well accepted by } \\
\text { staff (F-1A) } \\
\text { No viable technology solutions for high-risk, } \\
\text { high-volume patient handling tasks, eg } \\
\text { repositioning patient in bed or chair (B-2B) } \\
\text { Patients less likely to embrace new patient } \\
\text { handling technologies and practices at the } \\
\text { onset of the program (B-2G) }\end{array}$ \\
\hline
\end{tabular}

CON, control group; CT, controlled trial; INT, intervention group; OBS, observational study; RCT, randomised controlled trial. Type of barrier: B-2B represents a barrier (B), within environment (2), category B (convenience and easy accessibility).

of the influence of relevant barriers and facilitators during the implementation on the effectiveness of the primary preventive intervention.

This review has some limitations. First, the literature search may not have been complete since the review was restricted to studies published in English and available in two different electronic databases. The second electronic database provided nine (19\%) unique titles being considered for full review and resulted in three out of 19 studies included. Due to the possible incompleteness of reports, the importance of the current study lies in the identification of various factors that may hamper or facilitate the effectiveness of a primary preventive intervention rather than in the presentation of the exact distribution of individual and environmental factors that affect the effectiveness of patient handling interventions. Second, an essential inclusion criterion of this review was that a study should describe the effects of a primary preventive intervention on reduction in physical load, MSDs or musculoskeletal sick leave and report on relevant barriers and facilitators during the implementation of the intervention. This was decided because we wanted to assess which factors influence the implementation of primary interventions in healthcare and what the actual influence of these barriers and facilitators was on the effectiveness of the primary interventions. Thus, qualitative publications primarily focusing on barriers and facilitators in the appropriate implementation of interventions without addressing the intervention effects itself were not selected for this systematic review. Such publications may shed more light on the planning and processing of the implementation of interventions. ${ }^{8}$ It is expected, however, that the barriers and facilitators identified in this review will also be addressed to some extent in qualitative studies. Furthermore, this review was constricted to studies on primary preventive interventions aimed at patient handling in healthcare. Other interventions in healthcare organisations may involve other barriers and facilitators. Third, this systematic review refrained from assessing the methodological quality of the articles selected. This review does not address the effectiveness of interventions or exposure-response relationships for which the quality of the study may be a critical issue.
It could be hypothesised that better quality of the implementation process will result in higher effectiveness, but so far we lack the instruments to evaluate this. Finally, the chosen approaches of Rothschild ${ }^{16}$ and Shain and Kramer ${ }^{17}$ may have influenced the classification of the barriers and facilitators. For example, most barriers and facilitators were reported within the category "convenience and easy accessibility" (25 out of 61), which suggests a more detailed classification is needed. Nevertheless, the analysis presented shows the importance of both environmental as well as individual factors in the (successful) introduction of primary preventive interventions in the workplace and, thus, these factors need to be taken into account in studies evaluating the effectiveness of primary preventive interventions.

\section{Overview of barriers and facilitators}

The majority of the selected studies in this review identified several factors that could have interfered with the effective implementation of primary preventive interventions on patient handling in healthcare. Environmental factors seemed to be more important than individual factors, independent of the type of intervention. For the engineering interventions, almost $80 \%$ of the reported barriers and facilitators were categorised into environmental factors and for the multiple interventions this was approximately $90 \%$. Rather surprisingly, in evaluation studies on personal interventions through education and training, environmental factors (65\%) were more often reported than individual factors (35\%). Thus, it appears that the social and physical context in which the primary preventive intervention is implemented is of paramount importance.

\section{Influence of barriers and facilitators on effectiveness}

Only articles with quantitative data on physical load, MSD or their consequences in terms of sick leave were included in this review, anticipating that a quantitative analysis of the influence of barriers and facilitators on the effectiveness of primary preventive interventions in the workplace would be possible. However, it is remarkable that, considering the reported importance of these factors in the evaluation studies, only one 


\section{Main messages}

- Various barriers and facilitators in the appropriate implementation of primary preventive interventions were identified were only in qualitative terms, usually not included in the design of the study but collected afterwards, and not evaluated with respect to the effectiveness of the intervention.

- There is a clear need to evaluate the influence of barriers and facilitators on the effectiveness of primary preventive interventions.

study explicitly included the assessment of barriers in lift usage in the design of the study and none of the studies quantitatively evaluated the influence of these factors on the effectiveness of the primary intervention. ${ }^{12}$ Therefore, a quantitative analysis of the relative importance of personal and environmental factors in the effectiveness of interventions was unfortunately not possible in this review.

In five studies the barriers and facilitators were assigned retrospectively by the researcher as having possibly influenced the effectiveness of the primary intervention. Chhokar et al mentioned that the time required to alter work culture and to fully implement changes in patient handling practices may have prolonged the latency period between introducing ceiling lifts and the observed change in compensation claims ${ }^{19}$ Evanoff et al reported that the larger reduction in injuries observed in some facilities was likely due to a policy of mandatory lift usage and established care activities and patient characteristics. ${ }^{12}$ It is, however, difficult to determine the actual influence of these barriers and facilitators on the effectiveness of the primary intervention when researchers and stakeholders involved only provide a qualitative assessment. Fourteen studies identified barriers and facilitators in the implementation process of the primary intervention but did not report on their potential impact on the effectiveness of the intervention. The drawback of this approach is that the effectiveness of a primary intervention is separated from the implementation process. Theories on implementation in healthcare emphasise the importance of identifying obstacles to changing work practices and argue that their influence on the implementation process and the effectiveness of an intervention need to be assessed. ${ }^{34}$ There is still little guidance regarding the quantification of barriers and facilitators, but a necessary first step will be to rate the quality of the implementation. ${ }^{35} \mathrm{~A}$ second step will be more detailed assessment of individual and environmental factors, for example, the number of lifting aids available relative to the number of patients, the proportion of patient protocols with requirements on lifting procedures, and the percentage of nurses trained in the use of lifting aids.

The adoption and implementation of primary preventive interventions in healthcare require comprehensive approaches at different levels. ${ }^{9}$ Barriers that hamper the appropriate implementation of primary preventive interventions are complex, multifunctional and influenced at many levels of the healthcare system, including the individual, patient, social, organisational, economical and political. ${ }^{36}$ This requires the adaptation of implementation models, as in the approaches of Rothschild and Shain and Kramer. ${ }^{16}{ }^{17}$ In evaluation studies on the effectiveness of these primary interventions, it remains a challenge to incorporate important barriers and facilitators into the study design so as to enable a quantitative evaluation of their influence on the effectiveness of the interventions.

\section{Policy implications}

Workplace policies should target factors that hamper compliance and adherence to the appropriate implementation of primary preventive interventions.

In conclusion, various individual as well as environmental factors may influence the appropriate implementation of primary preventive interventions and, thus, the effectiveness of these interventions. Environmental factors were far more often reported than individual factors, independent of the type of intervention. The identified barriers and facilitators were only described in qualitative terms and were usually not included in the design of the study but collected afterwards. None of the studies presented a quantitative evaluation of the influence of relevant barriers and facilitators on the effectiveness of the primary intervention. Since many barriers and facilitators have been acknowledged as causing failure of the effective implementation of primary interventions on patient handling, there is a clear need to quantify the impact of these barriers and facilitators on the effectiveness of primary preventive interventions.

Funding: This study was funded by a grant from the Netherlands Organisation for Health Research and Development (ZonMw - grant number 63200014).

Competing interests: None.

\section{REFERENCES}

1. United States Bureau of Labor Statistics. Table 12. Number and median days of nonfatal occupational injuries and illnesses with days away from work involving musculoskeletal disorders by selected occupations, 2001. Available from http://www bls.gov/iif/oshwc/osh/case/ostb1155.pdf (accessed 16 March 2009).

2. Smedley J, Egger $P$, Cooper $C$, et al. Manual handling activities and risk of low back pain in nurses. Occup Environ Med 1995;52:160-3.

3. Burdorf A, Jansen JP. Predicting the long term course of low back pain and its consequences for sickness absence and associated work disability. Occup Environ Med 2006;63:522-9.

4. Dawson AP, McLennan SN, Schiller SD, et al. Interventions to prevent back pain and back injury in nurses: a systematic review. Occup Environ Med 2007;64:642-50.

5. Nelson A, Baptiste AS. Evidence-based practices for safe patient handling and movement. Orthop Nurs 2006;25:366-79.

6. Hignett $\mathbf{S}$. Intervention strategies to reduce musculoskeletal injuries associated with handling patients: a systematic review. Occup Environ Med 2003;60:E6.

7. Martimo KP, Verbeek J, Karppinen J, et al. Effect of training and lifting equipment for preventing back pain in lifting and handling: systematic review. BMJ 2008;336:429-31.

8. Roquelaure Y. Workplace intervention and musculoskeletal disorders: the need to develop research on implementation strategy. Occup Environ Med 2008;65:4-5.

9. Grol R, Grimshaw J. From best evidence to best practice: effective implementation of change in patients' care. Lancet 2003;362:1225-30.

10. Engkvist IL. Nurses' expectations, experiences and attitudes towards the intervention of a 'no lifting policy'. J Occup Health 2007:49:294-304.

11. Best M. An evaluation of Manutention training in preventing back strain and resultant injuries in nurses. Saf Sci 1997;25:207-22.

12. Evanoff B, Wolf $L$, Aton $E$, et al. Reduction in injury rates in nursing personnel through introduction of mechanical lifts in the workplace. Am J Ind Med 2003;44:451-7.

13. Ronald LA, Yassi A, Spiegel J, et al. Effectiveness of installing overhead ceiling lifts Reducing musculoskeletal injuries in an extended care hospital unit. AAOHN $J$ 2002;50:120-7.

14. Denis D, St-Vincent M, Imbeau D, et al. Intervention practices in musculoskeletal disorder prevention: a critical literature review. App/ Ergon 2008;39:1-14.

15. Zwerling C, Daltroy LH, Fine LJ, et al. Design and conduct of occupational injury intervention studies: a review of evaluation strategies. Am J Ind Med 1997;32:164-79.

16. Rothschild ML. Carrots, sticks and promises: a conceptual framework for the management of public health and the social issue behaviours. J Mark 1999;63:24-37.

17. Shain M, Kramer DM. Health promotion in the workplace: framing the concept; reviewing the evidence. Occup Environ Med 2004;61:643-8, 585.

18. Li J, Wolf L, Evanoff B. Use of mechanical patient lifts decreased musculoskeletal symptoms and injuries among health care workers. Inj Prev 2004;10:212-16.

19. Chhokar R, Engst C, Miller A, et al. The three-year economic benefits of a ceiling lift intervention aimed to reduce healthcare worker injuries. App/ Ergon 2005;36:223-9. 
20. Engst C, Chhokar R, Miller A, et al. Effectiveness of overhead lifting devices in reducing the risk of injury to care staff in extended care facilities. Ergonomics 2005;48:187-99.

21. Fujishiro $\mathbf{K}$, Weaver $\mathrm{JL}$, Heaney $\mathrm{CA}$, et al. The effect of ergonomic interventions in healthcare facilities on musculoskeletal disorders. Am J Ind Med 2005;48:338-47.

22. Garg A, Owen B. Reducing back stress to nursing personnel - an ergonomic intervention in a nursing-home. Ergonomics 1992;35:1353-75.

23. Miller A, Engst C, Tate RB, et al. Evaluation of the effectiveness of portable ceiling lifts in a new long-term care facility. App/ Ergon 2006;37:377-85.

24. Owen BD, Keene K, Olson S. An ergonomic approach to reducing back/shoulder stress in hospital nursing personnel: a five year follow up. Int J Nurs Stud 2002;39:295-302.

25. Yassi A, Cooper JE, Tate RB, et al. A randomized controlled trial to prevent patient lift and transfer injuries of health care workers. Spine 2001;26:1739-46.

26. Feldstein A, Valanis B, Vollmer W, et al. The back injury prevention project pilotstudy - assessing the effectiveness of back attack, an injury prevention program among nurses, aides, and orderlies. J Occup Environ Med 1993;35:114-20.

27. Johnsson C. Carlsson R, Lagerstrom M. Evaluation of training in patient handling and moving skills among hospital and home care personnel. Ergonomics 2002;45:850-65.

28. Lagerstrom M, Josephson M, Pingel B, et al. Evaluation of the implementation of an education and training programme for nursing personnel at a hospital in Sweden. Int J Ind Ergon 1998;21:79-90.
29. Lynch RM, Freund A. Short-term efficacy of back injury intervention project for patient care providers at one hospital. Am Ind Hyg Assoc J 2000:61:290-4.

30. Peterson EL, McGlothlin JD, Blue CL. The development of an ergonomics training program to identify, evaluate, and control musculoskeletal disorders among nursing assistants at a state-run veterans' home. J Occup Environ Hyg 2004;: 1:D10-16

31. Charney W, Simmons B, Lary $\mathrm{M}$, et al. Zero lift programs in small rural hospitals in Washington state: reducing back injuries among health care workers. AAOHN J 2006; $54: 355-8$

32. Knibbe JJ, Friele RD. The use of logs to assess exposure to manual handling of patients, illustrated in an intervention study in home care nursing. Int $\mathrm{J}$ Ind Ergon 1999;24:445-54.

33. Nelson A, Matz M, Chen FF, et al. Development and evaluation of a multifaceted ergonomics program to prevent injuries associated with patient handling tasks. Int J Nurs Stud 2006:43:717-33.

34. Bosse G, Breuer JP, Spies C. The resistance to changing guidelines - what are the challenges and how to meet them. Best Pract Res Clin Anaesthesiol 2006;20:379-95.

35. Molleman GRM, Peters LWH, Hosman $\mathrm{CMH}$, et al. Project quality rating by experts and practitioners: experience with Preffi 2.0 as a quality assessment instrument. Health Educ Res 2006;21:219-29.

36. Grol R, Wensing M. What drives change? Barriers to and incentives for achieving evidence-based practice. Med J Aust 2004;180(6 Suppl):S57-60. 